\title{
The Biological Effects of Psychotherapy in Major Depressive Disorders: A Review of Neuroimaging Studies
}

\author{
Gülfizar Sözeri-Varma, Filiz Karadă̆ \\ Department of Psychiatry, Faculty of Medicine, Pamukkale University, Denizli, Turkey \\ Email: filizlal@yahoo.com
}

Received July $21^{\text {st }}, 2012$; revised August $25^{\text {th }}, 2012$; accepted September $27^{\text {th }}, 2012$

\begin{abstract}
Major depressive disorder (MDD) is a syndrome, which is quite frequent in the society, can be recurrent and shows symptoms of emotional, cognitive and behavioral disorder. Brain imaging studies support that patients diagnosed with MDD suffer dysfunction in limbic structures such as frontal cortex, amygdala, hippocampus and cingulate cortex and basal ganglions that regulate these functions. Psychotherapy is an effective treatment option for prevention of recurrent depressive attacks as well as for acute treatment of depression. It is thought that psychotherapy shows its effect by focusing on misleading cognitions and emotional information processing processes that lead to rise and persistence of symptoms of depression, which in turn boosts problem solving and coping skills. Neurobiological reflections of clinical recovery achieved by psychotherapy are not yet well known. In this study, it is aimed to review cognitive behavioral psychotherapy (CBT), interpersonal psychotherapy (IPT) and psychodynamic psychotherapy methods used frequently in treatment of MDD, along with functional brain imaging studies performed on treated depressive patients. Studies show that CBT lead to changes in the prefrontal cortex, cingulate cortex and amygdala metabolisms and activities. Activity of the subgenual cingulate cortex, which takes part in the regulation of the limbic activity, seems to play an important role in the response to CBT like in the response to antidepressant treatment. It was found that interpersonal psychotherapy (IPT) ensures recovery of metabolism and blood flow in the prefrontal cortex, cingulate cortex and basal ganglions. It was observed that psychodynamic therapy ensured recovery of abnormal activities in especially the prefrontal cortex and cingulate cortex in MDD, similar to the CBT and IPT. There is need for more long-term, follow-up studies in this area.
\end{abstract}

Keywords: Depression; Psychotherapy; Cognitive Behavior Psychotherapy; Interpersonal Psychotherapy; Psychodynamic Psychotherapy; Neurobiology

\section{Major Depressive Disorder}

Major depressive disorder (MDD) is a syndrome widely seen in the population that subverts functionality of the individual and affects his/her life negatively, with basic symptoms of depressed mood, loss of interest and desire, along with anhedonia. Symptoms of MDD can be summarized in 3 main domains. In the mental-behavioral domain, it is possible to see loss of meaning of life with emotions of desperateness, unworthiness, seeing oneself inferior and retardation in thoughts and behaveiors in addition to these main symptoms. It is possible to see anxiety and tension, suicidal thoughts and attempts. In the cognitive domain, it is possible to see a decline in the capacity to focus thoughts on a topic, insufficiency of intellectual functions and problems in memory areas in particular. Seeing past deeds and achievements worthless and meaningless, self-accusation, pessimism, hopelessness are other frequent symptoms. In the physical domain, possible symptoms are loss of energy and fatigue, change in appetite, sleep disturbances, decline in sexual interest and desires, somatics symptoms such as headaches and back pains (Güleç, 2003; APA, 2005).

\section{Neurobiology of Major Depressive Disorder}

Disturbances in neurotransmitters such as noradrenalin and dopamine, neuroendocrine disturbances, circadian arrhythmia, genetic factors, and serotoninergic dysfunction in particular, play a role in MDD etiopathogenesis (Yüksel, 2003; Holtzheimer \& Mayberg, 2008).

Dysfunction of prefrontal cortex (PFC) and striatal structures that regulate the limbic system and the brain stem lies beneath the depressive symptoms. It is reported that volume changes occur in the PFC, hippocampus and striatum (Hastings et al., 2004; Zou et al., 2010; Malykhin et al., 2011), neurons and glias get damaged, number and dimensions of the neurons diminish (Rajkowska et al., 1999; Oh et al., 2011), and frontal hypoperfusion occurs (Drevets, 2000; Narita et al. 2004) in MDD. Lorenzetti and colleagues (2009) reviewed structural magnetic resonance imaging (MRI) studies that were conducted between 2002 and 2007. The authors found that reduction of volume in hippocampus, basal ganglia and PFC is a consistent finding in MDD. Especially, it was found that in patients, who suffer the disorder for a long time with recurrent episodes, regional brain volume has considerably been affected.

Phenomenological differences between patients with mood disorders is explained by the hypothesis of dysfunction between neural cycles, which is defined as the putative neural network model of mood disorder. This hypothesis is based on presence of functional disorder between neural networks in mood disorders. As a response to these dysfunctions, compensatory mechanisms appear in neuronal networks. Compensatory mechanisms 
may cause changes in the neuronal network that result in different symptoms. Disturbances in the limbic-thalamo-cortical cycle and limbic-cortical-striatal-pallidal-thalamic cycles that also cover these cycle, or in more general terms rise and/or decline in some synaptic activities in these structures is thought to be responsible for etiopathogenesis of MDD. It is pointed out that most consistent finding obtained from functional neuroimaging studies in patients with MDD is the decline in the frontal lobe functions. In MDD, there is an inverse relationship between the prefrontal activity and severity of depression during resting period. It is assumed that metabolic changes that take place are the lesion itself or an ongoing self-recovery attempt. For example, frontal hyperactivity may be an exaggerated or unsuitable compensatory process that results in psychomotor agitation or ruminative thoughts; and it may result in persistence of the negative mood by causing abnormal chronic activity of the limbic-subcortical structures. Frontal hypometabolism might be a result of insufficiency information or continuation of compensatory mechanisms that result in apathy, psychomotor retardation and disturbance of driving functions. Complete identification of contributions of adaptive and maladaptive compensatory responses may enable choice of optimal therapy option by taking different effects of different therapeutic methods into consideration (Drevetes, 1998; Mayberg, 2006; Holtzheimer \& Mayberg, 2008).

There are psychotherapy methods, whose effectiveness on depression is proved by research, and which has model-specific formulations and attaches importance to psycho-education and use according to guides. Most widely used of these are cognitive-behavioral psychotherapy, interpersonal psychotherapy and short-term psychodynamic psychotherapy. Common features of these methods are short-dated treatment protocols that last 2 to 4 months, ability to observe and measure the decline in the symptoms, and unique theoretical basis of each of the models (Driessen ve ark., 2007, Friedman ve Thase, 2009). For this reason, mentioned psychotherapy methods are thought to be suitable tools to research the brain activity changes that accompany depression therapy.

In this study, it is aimed to review the neurobiological effects of psychotherapies in unipolar major depressive disorder. Literature search revealed that studies in this field focus on applications of cognitive-behavioral psychotherapy, interpersonal psychotherapy and psychodynamic psychotherapy. Since research in this field is limited, all articles that could be accessed are included in the study.

\section{Cognitive Behavioral Psychotherapy and Neurobiology}

Cognitive behavioral psychotherapy (CBT) received most attention in the studies that deal with neurobiological effects of psychotherapies in MDD. CBT is an effective psychotherapy method commonly used for treatment of depression. According to CBT, maladaptive information processing processes, such as misleading beliefs and recurrent negative thoughts, over-generalization, over-personalization, selective abstraction, thought of all-or-nothing, lie under depression (Beck, 2005). In MDD, it is found that maladaptive cognitive processes such as ruminations and strongly negative self-focus is connected to hyperactivity of PFC and rostral anterior cingulate cortex (ACC) (Yoshimura, 2010). It is detected that while emotional decisions are made by depression patients, there is hypoactivity in the left and hyperactivity in the right of the dorsolateral prefrontal cortex (DLPFC) (Grimm, 2008). It is found that effective connections between PFC, ACC and amygdala got disturbed in patients with MDD. Regulative effect of PFC on amygdala becomes insufficient and bottom to up activity increases in the connections between amygdala and ACC, and between ACC and PFC. It is claimed that in MDD, reason behind the difficulty in coping with emotional stimuli is the breach of the connection between the prefrontal cortex and amygdala (Siegla 2007; Moses-Kolko, 2010; Carballedo, 2011; Lu, 2012).

Neurobiological effects of CBT were observed using functional imaging techniques (positron emission tomography scanning/PET and functional magnetic resonance imaging/fMRI) (Table 1). Goldapple and colleagues (2004) studies all brain metabolisms before and after the treatment with PET and compared psychotherapy and pharmacotherapy. In both treatment groups, similar levels of recovery were observed in the severity of the depression. In the psychotherapy group, hippocampus and dorsal cingulate metabolisms increased and PFC metabolism decreased in the direction of normalization. In the pharmacotherapy group, exactly opposite changes were observed as prefrontal activity increased and hippocampus and cingulate activity decreased. It was commented that there may be a relationship between the decline in ruminative thoughts and other dysfunctional thoughts achieved by psychotherapy and the decline in the PFC activity; and pharmacotherapy ensured repression of limbic activities and regulation of emotional reactivity. In a similar study, 12 patients diagnosed with MDD were applied CBT and 12 patients were applied venlafaxine treatment. After a treatment period of sixteen weeks, changes in brain metabolism were investigated by PET. In both treatment groups, it was found that orbitofrontal cortex and left medial PFC metabolisms decreased and right occipital-temporal cortex metabolism increased. Difference was detected in terms of effects on subgenual cingulate and caudate in the two treatment groups. It was concluded that subgenual cingulate might have an important role in response to the treatment (Kennedy et al., 2007).

Cingulate cortex plays an important role in depression therapy. In a study, hypermetabolism was detected on the interface between pre-treatment pregenual and subgenual cingulate cortex in the patients who did not respond to psychotherapy and venlafaxine treatment. However, hypometabolism was detected in the same region in the patients who responded to the treatment. It was argued that hyperactivity in the subgenual cingulate cortex might be an indication of resistance to both psychotherapies and pharmacotherapy (Konarski, 2009). A metaanalysis study showed that changes in the frontal and cingulate cortex metabolisms are consistent findings. To a lesser extent, changes in other limbic and sub-cortical regions (hippocampus, amygdala, posterior cingulate, striatum and thalamus) were reported. Frontal and cingulate cortex are divided into different regions according to anatomical, functional, structural and postmortem studies: dorsolateral and ventromedial prefrontal cortex, dorsomedial and ventrolateral prefrontal cortex, dorsomedial and ventromedial frontal cortex; dorsal, rostral, subgenual cingulate. It was found that pharmacological, cognitive and somatic therapies cause different changes in different regions of the prefrontal and cingulate cortex (Seminowicz et al., 2004).

In some studies, neurobiological effects of psychotherapies were investigated using functional Magnetic Resonance Imaging (fMRI) method. It has been determined that in major 
Table 1.

The studies of cognitive behaviour psychotherapy.

\begin{tabular}{|c|c|c|c|}
\hline Study & $\begin{array}{l}\text { Subjects, therapy, duration of } \\
\text { therapy }\end{array}$ & Imaging & Results \\
\hline $\begin{array}{l}\text { Goldapple and colleagues } \\
\qquad(2004)\end{array}$ & $\begin{array}{l}\text { unipolar MDD } \\
\text { CBT, n: } 17,15 \text { - } 20 \text { seans } \\
\text { paroksetine-treatment, n: } 13\end{array}$ & PET/resting-state & $\begin{array}{l}\text { CBT } \\
\text { Decreased metabolism } \\
\text { Dorsal, ventral, medial frontal cortex } \\
\text { Increased metabolism } \\
\text { Hippocampus, dorsal cingulate } \\
\text { Paroksetine treatment } \\
\text { Decreased metabolism } \\
\text { Hippocampal, subgenual cingulate } \\
\text { Increased metabolisma } \\
\text { Prefrontal cortex }\end{array}$ \\
\hline $\begin{array}{l}\text { Kennedy and colleagues } \\
\text { (2007) }\end{array}$ & $\begin{array}{c}\text { MDD } \\
\text { CBT, n: } 12 \\
\text { venlafaksine-treatment, n: } 12 \\
16 \text { weeks }\end{array}$ & PET/resting-state & $\begin{array}{l}\text { Both CBT and venlafaxine responders } \\
\text { Decreased metabolism } \\
\text { Bilaterally orbitofrontal cortex, left dorsomedial } \\
\text { prefrontal cortex } \\
\text { Increased metabolism } \\
\text { Right inferior occipital cortex }\end{array}$ \\
\hline $\begin{array}{l}\text { Konarski and colleagues } \\
\text { (2009) }\end{array}$ & $\begin{array}{c}\text { MDD } \\
\text { CBT, n: } 17 \\
16 \text { weeks } \\
\text { venlafaksine-treatment, } \mathrm{n}: 14\end{array}$ & PET/resting-state & $\begin{array}{l}\text { Nonresponders to CBT or venlafaksine, } \\
\text { Pre-treatment, } \\
\text { Hypermetabolism interface of the pregenual and } \\
\text { subgenual cingulate cortices }\end{array}$ \\
\hline $\begin{array}{l}\text { Siegle and colleagues } \\
\text { (2006) }\end{array}$ & $\begin{array}{c}\text { MDD } \\
\text { CBT, n: } 14 \\
\text { healthy control, } \mathrm{n}: 21\end{array}$ & PET/emotional stimuli & $\begin{array}{l}\text { CBT responders } \\
\text { Decreased reactivity } \\
\text { Subgenual cingulate cortex } \\
\text { Increased reactivity } \\
\text { Amigdala }\end{array}$ \\
\hline $\begin{array}{l}\text { Fu and colleagues } \\
\qquad(2008)\end{array}$ & $\begin{array}{l}\text { unipolar MDD } \\
\text { CBT, n: } 16 \\
\text { healthy control, n: } 16 \\
16 \text { weeks }\end{array}$ & fMRI/performance task & $\begin{array}{l}\text { Elevate amygdala activity and anterior cingulate activity } \\
\text { may be a predictor of treatment response to both } \\
\text { pharmacotherapy and CBT }\end{array}$ \\
\hline $\begin{array}{l}\text { Costafreda and colleagues } \\
\text { (2009) }\end{array}$ & $\begin{array}{c}\text { MDD } \\
\text { CBT, n: } 16\end{array}$ & fMRI/emotional stimuli & $\begin{array}{l}\text { Anterior cingulated cortex activity may be predictor of } \\
\text { the response to pharmacotherapy and CBT }\end{array}$ \\
\hline $\begin{array}{l}\text { Ritchey and } \\
\text { colleagues (2011) }\end{array}$ & $\begin{array}{l}\text { Unipolar-MDD } \\
\text { CBT, n: } 22 \\
\text { healthy control, } \mathrm{n}: 14 \\
30.3 \text { weeks }\end{array}$ & fMRI/emotional stimuli & $\begin{array}{l}\text { Prior to treatment, in MDD } \\
\text { Reduce activity in the PFC, } \\
\text { diminishe discrimination between emotional and neutral } \\
\text { items in the amygdala, caudate, and hippocampus } \\
\text { Post-treatment } \\
\text { Overall increase in PFC activation, enhanced arousal } \\
\text { responses in the amygdala, caudate, and hippocampus }\end{array}$ \\
\hline
\end{tabular}

Note: MDD: Major depressive disorder; CBT: Cognitive Behaviour Psychotherapy; PFC: prefrontal cortex; PET: Positron emission tomography scanning; fMRI: Functional magnetic resonance imaging.

depressive disorder there is a general decrease of activity in the ventromedial prefrontal cortex (PFC); that the distinction of emotional and neutral stimuli in amygdala, caudate, hippocampus decreases and that the response to negative stimuli in left anterior temporal lobe and right dorsolateral PFC in comparison to positive stimuli. Following CBT, MDD patients exhibited overall increases in ventromedial PFC activation, enhanced arousal responses in the amygdala, caudate, and hippocampus, and a reversal of valence effects in the left anterior temporal lobe (Ritchey et al., 2011). Fourteen patients with MDD and 21 healthy control subjects were compared in terms of activity during emotional response. It was found that in patients with MDD, both subgenual cingulate cortex and amygdala showed abnormal activity. Strong relationship was found between low reactivity in subgenual cingulate cortex, high reactivity in amygdala and the response to CBT. Decline in subgenual cingulate cortex activity before the therapy is a predictor for re- sponse to CBT and shows a deficit in regulation of this area. It is argued that CBT might be providing recovery by fixing the disturbances in the emotional regulation (Siegle et al., 2006). $\mathrm{ACC}$ is the first piece of the Papez circuit that is known to be associated with regulation of emotions. It is known that in depression patients, grey matter volume, blood flow and glucose metabolism decrease in the subgenual cingulate cortex (Drevets, 2008). Data at hand shows that cingulate cortex functions that get disturbed in MDD might be recovered by CBT.

The other study, patients with MDD, healthy individuals with cognitive vulnerability to depressive disorder and healthy control group were compared. In patients with MDD, it was found that amygdala response increased and DLPFC response decreased during emotional matching task compared to the healthy control group. Similarly, when the group with cognitive vulnerability was compared to the healthy control group, it was found that bilateral amygdala activity was higher and bilateral 
DLPFC activity was lower. These findings show that response to an emotional stimulus in depression may be in the form of hypoactivation of the prefrontal cortex and hyperactivation of amygdala. It is pointed out that they indicate a disorder in cognitive regulation of emotions by neural network in individuals with cognitive vulnerability to depression (Zhong, 2011). Continuous activity of amygdala was found to be more related to the intensity of the ruminative thoughts than to the severity of depression. It is asserted that continuous high reactivity of amygdala and continuous low reactivity of subgenual cingulate cortex reflect as ruminations on the clinic (Siegle et al., 2007). $\mathrm{Fu}$ and colleagues (2008) reported that amygdala-hippocampus activity is relatively high compared to the healthy group during depressive episode and there is a correlation between the basal ACC activity and the response to the therapy. A similar study supports that in depression neural network that contains ACC is important for response to the CBT, and that changes in the ACC activity may be predictor of the response to pharmacotherapy and CBT (Costafreda et al., 2009). CBT possibly shows its effect more controlled information processing processes replace emotional responses, automatic limbic reactions are prevented and role of inhibitor driving mechanisms increases (Derubeus, 2008; Holtzheimer \&Mayberg, 2008).

Findings derived from these studies show that CBT ensures recovery in the maladaptive information processing processes in MDD by causing changes in the PFC, ACC, and amygdala metabolisms. There are clues that metabolism and activity changes in the cingulate cortex (especially in the subgenual area) might be decisive on response to the therapy.

\section{Interpersonal Psychotherapy and Neurobiology}

Interpersonal psychotherapy (IPT) aims to alleviate depression by raising quality of interpersonal world of the patient. Phenomenological formulation of this method is based on social environment of the individual. Depression is associated with current interpersonal relationship problems. The patient is assisted to gain social skills so that she/he can solve his/her interpersonal relationships. In IPT, 12 to16-week sessions are applied and 4 main topics are focused on: 1) Unresolved Grief: The patient is encouraged to mourn after the relative lost and establish new relationships; 2) Role conflict: In case of social role conflict, the individual is encouraged to reevaluate the difficulties and search for ways of solution; 3) Role transitions: Possible gains for the patient from role transitions are worked on; 4) Interpersonal deficiencies: When interpersonal conflicts are evident, psychotherapy aims at overcoming social isolation. Another characteristic of this method is supporting of strong aspects of the patient (Alkan, 2007; Friedman \& Thase, 2009).

Three studies done in this area has been reached (Table 2). A study conducted by Brodly and colleagues (2001a) compared brain metabolism of 24 patients suffering major depressive disorder with a healthy control group of 16 people (using PET). Ten patients with depression were applied paroxetine and 14 patients were applied IPT. Patients who had MDD before the treatment had PFC, caudate and thalamus metabolisms higher than and temporal lobe metabolism lower than the control group. In both groups, PFC (bilateral in the group taking paroxetine and right in the group receiving IPT) and left anterior cingulate gyrus metabolisms decreased and left temporal lobe metabolism increased to return to normal. In the other study of the same author, metabolic values of 14 patients who were applied IPT for 12 weeks were compared to 24 patients who took paroxetine. Correlation was found between recovery from anxiety, psychomotor retardation, tension and fatigue symptoms and the decline in the ventral frontal lobe metabolism; between recovery from anxiety and tension symptoms and the decline in ventral anterior cingulate gyrus and anterior insula activity; between psychomotor retardation and the increase of dorsal anterior cingulate activity; and between cognitive disturbance and the increase of DLPFC metabolism. It was concluded that findings supported limbic-cortical dysregulation theory in MDD, metabolic changes occurred in the frontal zone in depression and IPT fixed these (Brody et al., 2001b).

In another study, 13 patients diagnosed with MDD and suffer medium to severe depression were applied IPT and 15 patients were applied $75 \mathrm{mg} / \mathrm{g}$ venlafaxine. After 6 weeks, single photon emission computed tomography (SPECT) scan was taken to evaluate brain blood flow. In both groups, severity of depression decreased. In the venlafaxine group, activity was detected in the right posterior temporal and right basal ganglia; and in the IPT group activity was detected in the right posterior cingulate and right basal ganglia. Increase in limbic blood flow was detected in the IPT group, and increase in basal ganglion blood flow was detected in both treatment groups (Martin et al., 2001).

Although there are lower number of studies in this field, the findings support that IPT ensure recovery of the metabolism and blood flow in the prefrontal cortex, cingulate cortex and basal ganglia. More research is needed in this field.

\section{Psychodynamic Therapies and Neurobiology}

Psychodynamic psychotherapy model is based on the idea that depression is related to unconscious conflicts and desires. According to this, interpersonal relationships are closely related to developmental characteristics brought from childhood and these characteristics are seen as transference in therapeutic relationship. Psychodynamic therapy focuses on how present losses and stressors revive past losses and traumas (Gabbard \& Bennett, 2009). Although there are many opinions and theories in this field, these will not be discussed here. Psychodynamic psychotherapy can be applied short or long term. Long-term psychodynamic psychotherapy aims to provide an insight and reevaluation of experiences related to the depressive pathology. In the first and one study in this field, changes caused by psychodynamic psychotherapy on left anterior hippocampus, amygdala, subgenual cingulate and medial prefrontal cortex regions are investigated using fMRI in MDD (Table 3). Depression patients were applied psychodynamic therapy for 15 months and activation values obtained before the therapy was compared with those obtained after the therapy. After psychotherapy, it was found that depressive symptoms decreased, accompanied by a decline of activity in the cingulate and medial prefrontal cortex, which was high before the therapy (Buchheim et al., 2012). Findings obtained through psychodynamic psychotherapy show that abnormal activities in the prefrontal cortex and cingulate cortex in the depression are regulated, which supports results of the CBT and IPT.

\section{Discussion}

In major depressive disorder, emotional information processing mechanisms are disrupted in relation to the functional anomalies in the prefrontal cortex, anterior cingulate cortex, 
Table 2.

The studies of interpersonal psychotherapy.

\begin{tabular}{|c|c|c|c|}
\hline Study & Subjects, therapy, duration of therapy & Imaging & Results \\
\hline $\begin{array}{l}\text { Brodly and } \\
\text { colleagues } \\
\text { (2001a) }\end{array}$ & $\begin{array}{c}\text { unipolar MDD } \\
\text { IPT, n: } 14 \\
\text { paroksetine-treatment, n: } 10 \\
\text { healthy control, n: } 16 \\
12 \text { weeks }\end{array}$ & PET/resting & $\begin{array}{l}\text { Before treatment, in MDD } \\
\text { Increased metabolism } \\
\text { Prefrontal kortex, caudate, thalamus } \\
\text { Decreased metabolism } \\
\text { Temporal lobe } \\
\text { After treatment, in MDD } \\
\text { Decreased metabolism } \\
\text { IPT group } \\
\text { Right prefrontal cortex, left cingulate gyrus } \\
\text { Paroksetine group } \\
\text { Bilateral prefrontal cortex, left cingulate gyrus } \\
\text { Increased metabolism } \\
\text { Left temporal lobe }\end{array}$ \\
\hline $\begin{array}{l}\text { Brodly and } \\
\text { colleagues } \\
\text { (2001b) }\end{array}$ & $\begin{array}{c}\text { MDD, } \mathrm{n}: 39 \\
\text { IPT or paroksetine-treatment, } \\
12 \text { weeks }\end{array}$ & PET/resting & $\begin{array}{l}\text { Different depressive symtoms improvement associated with } \\
\text { Decreased metabolism } \\
\text { Ventral frontal lobe ventral anterior cingulate gyrus } \\
\text { anterior insula activity } \\
\text { Increased metabolism } \\
\text { dorsal anterior cingulate dorsolateral prefrontal cortex }\end{array}$ \\
\hline $\begin{array}{l}\text { Martin and } \\
\text { colleagues } \\
\text { (2001) }\end{array}$ & $\begin{array}{c}\text { MDD } \\
\text { IPT, n: } 13 \\
\text { venlafaksine-treatment, n: } 15 \\
6 \text { weeks }\end{array}$ & SPECT & $\begin{array}{l}\text { IPT } \\
\text { activity, right posterior cingulate, basal ganglia increase } \\
\text { limbic blood flow and basal ganglion } \\
\text { Venlafaksine-treatment } \\
\text { Activity, right posterior temporal, basal ganglia increase } \\
\text { Basal ganglion blood flow }\end{array}$ \\
\hline
\end{tabular}

Note: IPT: Interpersonal psychotherapy, PET: Positron emission tomography, SPECT: single photon emission computed tomography.

Table 3.

The studies of psychodynamic psychotherapy.

\begin{tabular}{|c|c|c|c|}
\hline Study & Subjects, therapy, duration of therapy & Imaging & Results \\
\hline $\begin{array}{l}\text { Buchheim and } \\
\text { colleagues (2012) }\end{array}$ & $\begin{array}{c}\text { recurrent MDD } \\
\text { long-term psychodynamic psychotherapy, n: } 16 \\
\text { healthy control, n: } 17 \\
15 \text { months }\end{array}$ & $\begin{array}{c}\text { fMRI/ } \\
\text { emotional stimuli }\end{array}$ & $\begin{array}{l}\text { Before treatment, in MDD } \\
\text { Increased activation } \\
\text { Hippocampus, amygdala subgenual cingulate medial } \\
\text { prefrontal cortex } \\
\text { After treatment } \\
\text { Decreased activation } \\
\text { The same areas }\end{array}$ \\
\hline
\end{tabular}

Note: fMRI: Functional magnetic resonance imaging.

amygdala and other limbic system structures. In general, it is understood that the controlling effect of the prefrontal cortex on the cingulate cortex and amygdala decreases and that the functional relationship between these structures is disrupted. However, it is possible to interpret some of the functional changes in neural cycles as a result of the compensatory mechanisms. The determination of the functional changes caused by psychotherapies in brain structures related with emotional processes is very exciting. Even though the number of studies in this field is increasing, it is still fairly low. The studies that have been carried out show that these three psychotherapy methods (cognitive behavioral psychotherapy, interpersonal psychotherapy, psychodynamic psychotherapy) are effective in the treatment of depression and that they provide a similar level of amelioration in depressive symptoms with antidepressants. The theoretical explanation of depression pathophysiology and the methods used for treatment differ between these three psychotherapy methods. However, it is observed that similar changes in the brain structure arise (despite the fact that it is difficult to generalize due to the small amount of data). New studies are required examining the relationship between the symptoms that are recovered via the applied psychotherapy method and the changes in the brain.

Since there is limited number of studies on neurobiological effects of psychotherapies, the data is derived from limited number of patients. More research should be conducted to generalize the findings. It is observed that the studies focus on short-term effects of psychotherapies. In fact, long-term evaluation of effects of psychotherapies on emotions, thoughts and behaviors may be more enlightening. In a disorder with such high risk of recurrence, there is need for studies aimed to investigate long-term results of psychotherapies and their effects on recurrence.

\section{Conclusion}

It is known that both biological and psychosocial factors play a role in emergence of depression, and both drugs and psychotherapy have effects through different mechanisms on patients. Researches that investigate neurobiological effects of psycho- 
therapies show that different psychotherapy methods lead to metabolism and activity changes in the direction of recovery in especially the cingulate cortex, prefrontal cortex and amygdala.

\section{REFERENCES}

Alkan, M. (2007) Interpersonal psychotherapy of major depression and recurrent depression. Journal of Internal Medical Sciences, 3, 52-59.

American Psychiatric Association (1994). Diagnostic and statistical manual of mental disorders (4th ed.). Washington: American Psychiatric Association.

Beck, A. T. (2005). Cognitive therapy and emotional disorders. In A. Türkcan (Trans.), T. Özakkaş (Ed.), Istanbul: Litera Yayıncılık.

Brody, A. L., Saxena, S., Stoessel, P., Gillies, L. A., Fairbanks, L. A., Alborzian, S., Phelps, M. E., Huang, S.-C., Wu, H.-M., Ho, M. L., Ho, M. K., Au, S. C., Maidment, K., \& Lewis, R. (2001a). Regional brain metabolic changes in patients with major depression treated with either paroxetine or interpersonal therapy: Preliminary findings. Archives of General Psychiatry, 58, 631-640. doi:10.1001/archpsyc.58.7.631

Brody, A. L., Saxena, S., Mandelkern, M. A., Fairbanks, L. A., Ho, M. L., \& Baxter, L. R. (2001b). Brain metabolic changes associated with symptom factor improvement in major depressive disorder. Biological Psychiatry, 50, 171-178. doi:10.1016/S0006-3223(01)01117-9

Buchheim, A. L., Viviani, R., Kessler, H., Kächele, H., Cierpka, M., Roth, G., George, C., Kernberg, O.F., Bruns, G., \& Taubner, S. (2012). Changes in prefrontal-limbic function in major depression after 15 months of long-term psychotherapy. PLoS One, 7, e33745. doi:10.1371/journal.pone.0033745

Carballedo, A., Scheuerecker, J., Meisenzahl, E., Schoepf, V., Bokde, A., Möller, H. J., Doyle, M., Wiesmann M, \& Frodl, T. (2011). Functional connectivity of emotional processing in depression. Journal of Affective Disorders, 134, 272-279. doi:10.1016/j.jad.2011.06.021

Costafreda, S. G., Khanna, A., Mourao-Miranda, J., \& Fu, C. H. (2009). Neural correlates of sad faces predict clinical remission to cognitive behavioural therapy in depression. Neuroreport, 6, 637-641. doi:10.1097/WNR.0b013e3283294159

DeRubeis, R. J., Siegle, G. J., \& Hollon, S. D. (2008). Cognitive therapy versus medication for depression: Treatment outcomes and neural_mechanisms. Nature Reviews Neuroscience, 9, 788-796. doi: $10.1038 / \mathrm{nrn} 2345$

Drevets, W. C. (1998). Functional neuroimaging studies of depression: the anatomy of melancholia. Annual Review of Medicine, 49, 341361. doi:10.1146/annurev.med.49.1.341

Drevets, W. C. (2000). Neuroimaging studies of mood disorders. Biological Psychiatry, 48, 813-829. doi:10.1016/S0006-3223(00)01020-9

Drevets, W. C., Savitz, J., \& Trimble, M. (2008) The subgenual anterior cingulate cortex in mood disorders. CNS Spectrums, 13, 663681.

Driessen, E., Van, H. L., Schoevers, R. A. Cuijpers P., van Aalst G., Don F. J., Hendriksen M., Kool, S., Molenaar, P. J., Peen, J., \& Dekker, J. J. (2007). Cognitive behavioral therapy versus short psychodynamic supportive psychotherapy in the outpatient treatment of depression: A randomized controlled trial. BMC Psychiatry, 7, 1-14. doi:10.1186/1471-244X-7-58

Friedman, E. S., \& Thase, M. E. (2001) Depression-oriented psychotherapies. Gabbard's treatments of psychiatric disorders (Turkish) In G. O. Gabbard (Ed.), K. Alptekin, \& Ö. Öztürk (Trans. Ed.), Veri Medikal Yayıncılık (pp. 409-431). Ankara.

Fu, C. H., Williams, S. C., Cleare, A. J., Scott, J., Mitterschiffthaler, M. T., Walsh, N. D., Donaldson, C., Suckling, J., Andrew, C., Steiner, H., \& Murray, R. M. (2008). Neural responses to sad facial expressions in major depression following cognitive behavioral therapy. Biological Psychiatry, 64, 505-512. doi:10.1016/j.biopsych.2008.04.033

Gabbart, G. O., \& Bennett, T. J. (2001). Psychodynamic psychotherapy of depression. Gabbard's treatments of psychiatric disorders (Turk- ish). In G. O. Gabbard (Ed.), K. Alptekin, \& Ö. Öztürk (Trans. Ed.), Veri Medikal Yayıncılık (pp. 433-438). Ankara.

Goldapple, K., Segal, Z., Garson, C., Lau, M., Bieling, P., Kennedy, S., \& Mayberg, H. (2004). Modulation of cortical-limbic pathways in major depression: Treatment-specific effects of cognitive behavior therapy. Archives of General Psychiatry, 61, 34-41. doi:10.1001/archpsyc.61.1.34

Grimm, S., Beck, J., Schuepbach, D., Hell, D., Boesiger, P., Bermpohl, F., Niehaus, L., Boeker, H., \& Northoff, G. (2008). Imbalance between left and right dorsolateral prefrontal cortex in major depression is linked to negative emotional judgment: An fMRI study in severe major depressive disorder. Biological Psychiatry, 63, 369-376. doi:10.1016/j.biopsych.2007.05.033

Güleç, C. (2003). Psychiatry and $A B C$ of psychotherapies. Ankara: Hekimler Yayın Birliği.

Hastings, R. S., Parsey, R. V., Oquendo, M. A., Arango, V. \& Mann, J. J. (2004). Volumetric analysis of the prefrontal cortex, amygdala, and hippocampus in major depression. Neuropsychopharmacology, 29, 952-959. doi:10.1038/sj.npp.1300371

Holtzheimer, P. E., \& Mayberg, H. S. (2008). Neuropsychiatric aspects of mood disorders (pp. 1003-1024). Arlington, VA: The American Pscyhiatry Publishing.

Kennedy, S. H., Konarski, J. Z., Segal, Z. V., Lau, M. A., Bieling, P. J., McIntyre, R. S., \& Mayberg, H. S. (2007). Differences in brain glucose metabolism between responders to CBT and venlafaxine in a 16-week randomized controlled trial. American Journal of Psychiatry, 164, 778-788. doi:10.1176/appi.ajp.164.5.778

Konarski, J. Z., Kennedy, S. H., Segal, Z. V., Lau, M. A., Bieling, P. J., McIntyre, R. S., \& Mayberg, H. S. (2009). Predictors of nonresponse to cognitive behavioural therapy or venlafaxine using glucose metabolism in major depressive disorder. Journal of Psychiatry and Neuroscience, 34, 175-180.

Lorenzetti, V., Allen, N. B., Fornito, A., \& Yücel, M. (2009). Structural brain abnormalities in major depressive disorder: A selective review of recent MRI studies. Journal of Affective Disorders, 117, 1-17. doi:10.1016/j.jad.2008.11.021

Lu, Q., Li, H., Luo, G., Wang, Y., Tang, H., Han, L., \& Yao, Z. (2012). Impaired prefrontal-amygdala effective connectivity is responsible for the dysfunction of emotion process in major depressive disorder: A dynamic causal modeling study on MEG. Neuroscience Letters, 523, 125-130. doi:10.1016/j.neulet.2012.06.058

Malykhin, N. V., Carter, R., Hegadoren, K. M., Seres, P., \& Coupland, N. J. (2012). Fronto-limbic volumetric changes in major depressive disorder. Journal of Affective Disorders, 136, 1104-1113. doi:10.1016/j.jad.2011.10.038

Martin, S. D., Martin, E., Rai S. S., Richardson, M. A., \& Royall, R. (2001). Brain blood flow changes in depressed patients treated with interpersonal psychotherapy or venlafaxine hydrochloride: Preliminary findings. Archives of General Psychiatry, 58, 641-648. doi:10.1001/archpsyc.58.7.641

Mayberg, H. S. (2006). Braing imaging. Mood disorders reference book. In D. J. Stein, D. J. Kupfer, \& A. F. Schatzberg (Eds.), Arlington, VA: The American Pscyhiatry Publishing, 219-234.

Moses-Kolko, E. L., Perlman, S. B., Wisner, K. L., James, J., Saul, A. T., \& Phillips, M. L. (2010) Abnormally reduced dorsomedial prefrontal cortical activity and effective connectivity with amygdala in response to negative emotional faces in postpartum depression. American Journal of Psychiatry, 167, 1373-1380. doi:10.1176/appi.ajp.2010.09081235

Narita, H., Odawara, T., Iseki, E., Kosaka, K., \& Hirayasu, Y. (2004). Psychomotor retardation correlates with frontal hypoperfusion and the Modified Stroop Test in patients under 60-years-old with major depression. Psychiatry and Clinical Neurosciences, 58, 389-395. doi:10.1111/i.1440-1819.2004.01273.x

Oh, D. H., Son, H., Hwang, S., \& Kim, S. H. (2012). Neuropathological abnormalities of astrocytes, gabaergic neurons, and pyramidal neurons in the dorsolateral prefrontal cortices of patients with major depressive disorder. European Neuropsychopharmacology, 22, 330338. doi:10.1016/j.euroneuro.2011.09.001

Rajkowska, G., Miguel-Hidalgo, J. J., Wei, J. Dilley, G., Pittman, S. D., 
Meltzer, H. Y., Overholser, J. C., Roth B. L., \& Stockmeier, C. A. (1999). Morphometric evidence for neuronal and glial prefrontal cell pathology in major depression. Biological Psychiatry, 45, 10851098. doi:10.1016/S0006-3223(99)00041-4

Ritchey, M., Dolcos, F., Eddington, K. M., Strauman, T. J., \& Cabeza, R. (2011) Neural correlates of emotional processing in depression: Changes with cognitive behavioral therapy and predictors of treatment response. Journal of Psychiatric Research, 45, 577-587.

doi:10.1016/j.jpsychires.2010.09.007

Seminowicz, D. A., Mayberg, H. S., McIntosh, A. R., Goldapple, K., Kennedy, S., Segal, Z., \& Rafi-Tari, S. (2004). Limbic-frontal circuitry in major depression: A path modeling metanalysis. Neuroimage, 22, 409-418. doi:10.1016/j.neuroimage.2004.01.015

Siegle, G. J., Carter, C. S., \& Thase, M. E. (2006). Use of fMRI to predict recovery from unipolar depression with cognitive behavior therapy. American Journal of Psychiatry, 163, 735-738.

doi:10.1176/appi.ajp.163.4.735

Siegle, G. J., Thompson, W., Carter, C. S., Steinhauer, S. R., \& Thase, M. E. (2007). Increased amygdala and decreased dorsolateral pre- frontal BOLD responses in unipolar depression: related and independent features. Biological Psychiatry, 61, 198-209. doi:10.1016/j.biopsych.2006.05.048

Yoshimura, S., Okamoto, Y., Onoda, K., Matsunaga, M., Ueda, K., Suzuki, S., \& Shigeto,Y. (2010). Rostral anterior cingulate cortex activity mediates the relationship between the depressive symptoms and the medial prefrontal cortex activity. Journal of Affective Disorders, 122, 76-85. doi:10.1016/j.jad.2009.06.017

Yüksel, N. (2003). Anti-depressant drugs. Psychopharmacology (2nd ed., pp. 169-285), Ankara: Çizgi Tıp Yayınevi.

Zhong, M., Wang, X., Xiao, J., Yi, J., Zhu, X., Liao, J., Wang, W., \& Yao, S. (2011) Amygdala hyperactivation and prefrontal hypoactivation in subjects with cognitive vulnerability to depression. Biological Psychiatry, 88, 233-242. doi:10.1016/j.biopsycho.2011.08.007

Zou, K., Deng, W., Li, T., Zhang, B., Jiang, L., Huang, C., Sun, X., \& Sun, X. (2010). Changes of brain morphometry in first-episode, drug-naive, non-late-life adult patients with major depression: An optimized voxel-based morphometry study. Biological Psychiatry, 67, 186-188. doi:10.1016/j.biopsych.2009.09.014 